\title{
Design Processes in Cultural and Creative Industries' Oriented Development: A Regional Case
}

Flaviano Celaschi ${ }^{1}$

Alma Mater Studiorum

— Università di Bologna

flaviano.celaschi@unibo.it

ORCID 0000-0002-5793-3480

\author{
Elena Vai ${ }^{1}$ \\ Alma Mater Studiorum \\ - Università di Bologna \\ elena.vai@unibo.it \\ ORCID 0000-0001-5953-3256
}

\begin{abstract}
The paper investigates the role of design as mediator in between culture, creativity, industry and top down policies. In that respect, it is responsible for enabling the creation of $\mathrm{CCl}$ ecosystems, overcoming the traditional antagonism between culture and economy, creativity and industry.

After defining the CCl's phenomenon on a European scale, the contribution tries to describe how design is part of this phenomenon but its nature does not belong neither to culture or creativity nor industry, but at the intersection of the three, thanks to its ability of integrating different knowledge and interests within the production processes, multiplying values.

Through the description of various creative ecosystem models, the paper aims to establish the interactive role of design processes, practices and design cultures in the creation of these $\mathrm{CCl}$ systems within the Smart Specialization Strategy (S3), to enhance the cultural and creative vibrancy and metabolism in cities.
\end{abstract}

\section{Keywords}

Advanced Design and CCl

Design mediation

$\mathrm{CCl}$ ecosystems

Regional development 


\section{Europe's Cultural and Creative Sectors and Industries}

Europe has roots, histories, skills, traditions and a cultural and creative heritage rich in diversity.

This heritage is recognised worldwide as a common value that defines the European identity, that of different countries, cities and citizens.

Europe in the last two decades has implemented policies to preserve this heritage, recognising the Cultural and Creative Industries (CCI) "essential for inclusive economic growth, reducing inequalities and achieving the goals set out in the 2030 Sustainable Development Agenda" (Convention on the Protection and Promotion of the Diversity of Cultural Expressions, 2005), trying to name them (European Agenda for Culture, 2007), mapping (Lhermitte et al., 2015), clustering (Throsby, 2001; Montalto et al., 2019) and enhancing (Official launch of the European Year of Creativity and Innovation, 2009; New European Agenda for Culture, 2018; Call for Proposals EIT KIC Culture and Creativity, 2021).

Since the emergence of the knowledge economy, $\mathrm{CCl}$ have become a sector that has developed globally, appreciated for its experimental nature in creating innovation in cities (Landry \& Bianchini, 1995), for its dynamism, flexibility and ability to bring together creative communities (Florida, 2003), to reactivate spaces, for its capacity to build new economic models (Howkins, 2001/2013), to experiment with new trades and to drive the digital economy, to bring multi stakeholder partnerships into play, to activate new models for relations between supranational creative districts (CREADIS3 Project, 2020), to demonstrate resilience (European Commission, 2016) especially in the context of major financial, economic, political and social crises, such as the one we have been experiencing since 2007, amplified last year by the COVID-19 pandemic.

However, it is only in the last decade that Europe has recognised the strategic productive role of the $\mathrm{CCl}$, a sector with a strong identity that manifests a typically European way of enhancing goods and services by integrating elements of creativity and culture into them.

Already in 2007, the European Commission adopted the first European Agenda for Culture which emphasised "that culture and creativity are important drivers for personal development, social cohesion, economic growth, creation of jobs, innovation and competitiveness" and endorsed three strategic objectives with a view to defining a common European Agenda for Culture promoting cultural diversity and intercultural dialogue, promoting culture as a catalyst for creativity for growth and jobs, promoting culture as a vital element in the Union's international relations (Official Journal of the European Union, 2007).

Replaced by the New European Agenda for Culture (2018), the update document considered the evolution of the cultural sector in relation to the impact of digital technologies, changing models in the governance of culture and the need to support the innovative potential of the cultural and creative sector, in the light of changing socio-economic conditions, by electing 2018 as the European Year of Cultural Heritage.
Flaviano Celaschi is author of Research Methodology and Characteristics of the Emilia-Romagna Region and Conclusions. Elena Vai is author of Europe's Cultural and Creative Sectors and Industries and Toward a New Cultural and Creative Industries' Ecosystem. 
Nevertheless, the difficulty in defining the cultural and creative sectors at European level (Gaiani, 2017) is actually impeding the process of fully recognising them and building communicating ecosystems. Indeed, the cultural and creative sectors include all tangible and intangible sectors whose activities are based on cultural values or other individual or collective creative artistic expressions and are defined in regulations of the Creative Europe Programme 2021-2027 (2018). It is also for this reason that the mapping process started in the last decade (Bakhshi et al., 2013) in order to measure the impact of the sector in a comparable and systematic way at the European scale but it is to be considered a challenge due to the lack of shared definitions and tools (KEA \& PPMI, 2019; Lhermitte et al., 2021).

The reading of $\mathrm{CCl}$ analysed by eleven sectors (advertising, architecture, books, gaming, movie, music, newspapers and magazines, performing arts, radio, TV, visual arts) adopted by UNESCO (2005), which defines $\mathrm{CCl}$ as those activities "whose principal purpose is production or reproduction, promotion, distribution or commercialisation of goods, services and activities of a cultural, artistic or heritage-related nature", seems today to be reductive if divided into cultural industries and creative industries, in favour of a reading by tags of competences, skills, tools, enabling technologies employed and behaviours activated.

Other critical issues lie in the gap between the adoption of European policies in support of $\mathrm{CCl}$, despite the shift of municipal interest from urban development of cities towards the production of cultural content, the complexity of the funding model through the new Horizon Europe 2021-2027 programme and the fragmented nature of $\mathrm{CCl}$. Indeed, the $\mathrm{CCl}$ sector is a field in which collaboration between institutional (policy makers), private (professionals, entrepreneurs, citizens), and educational actors (universities and research centres) is nowadays considered a crucial factor for the survival of individuals and of the whole ecosystem, even more than determining the increase of their innovation potential, which is vital for the continuous development of the cities in which they operate.

This is a fragile ecosystem, made up of freelancers who do not fall into protected and unionised categories and who risk disappearing also for this reason. The COVID-19 health emergency was the occasion through various reports to make it clear how independent cultural operators, the first to be promoters of cultural and creative metabolism through experimentation, prototypes, events and festivals, are assimilated to the categories of the "invisible". However, these categories together account for 4\% of GDP in Europe in terms of total turnover, with a turnover of 643 billion euros and a total added value of 253 billion euros (Lhermitte et al., 2021). Fundamental players in the system of culture and creativity (performing arts, cinema, publishing), heritage (reactivation, temporary uses, creative heritage), well-being and personal care, food and tourism, whose parameters have always defined the degrees of evolution of every civilisation. 


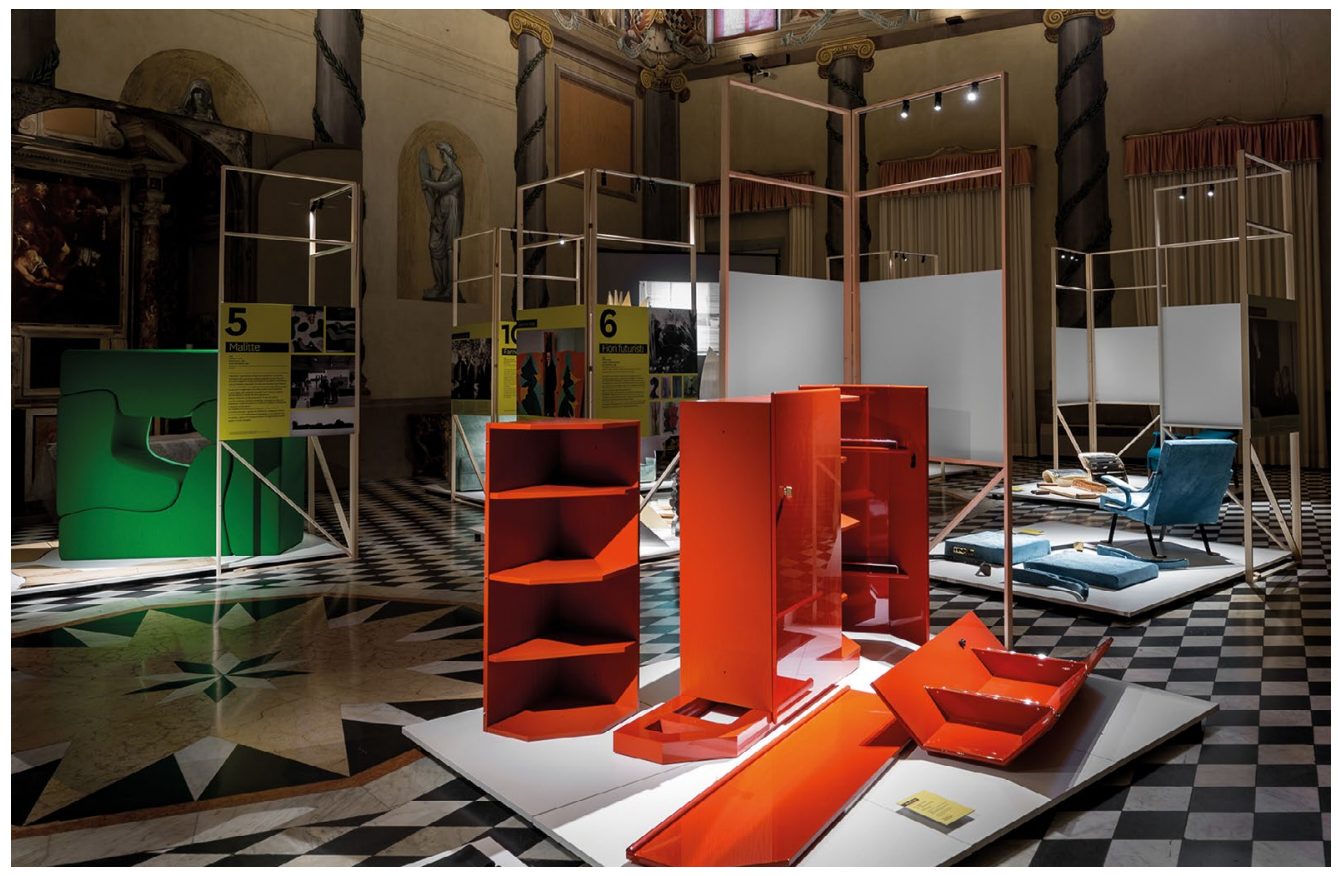

\section{Toward a New Cultural and Creative Industries' Ecosystem}

Since the emergence of the information and knowledge economy thanks to global access to internet, the $\mathrm{CCl}$ designers and performers, the models of production of product-services (design, fashion, publishing, architecture) and of works (cinema, theatre, music, live performances), the models of distribution and use of their products and services, which are responsible for defining the cultural and creative vocations of territories, have changed, and with them the cities which have been transformed into experimental living labs.

On a European scale, one of the signs of the growing importance of describing territories in terms of the $\mathrm{CCl}$ system was the establishment of UNESCO Creative Cities Network (UCCN, 2004), which was faced with the need to materialise values, knowledge and heritage through events, festivals, networks of actors and spaces.

Partly to meet this need, over the last two decades, design has seen its scope extended from product design to services, behaviour and events, taking on the role of mediating knowledge, a set of practices, tools and processes that allow culture, creativity and $\mathrm{CCl}$ to be considered today as agents of change and rebirth in the new normal era.

The creation of event formats for the enhancement of $\mathrm{CCl}$, such as triennial (Reciprocity design Liège), biennal (La Biennale di Venezia), design weeks (World Design Weeks), has distinguished more than forty cities around the world that have become the fulcrum of ecosystems for their territories (Milan, Venice, Bologna, London, Paris, Berlin, Stockholm, Vienna, Barcelona, Eindhoven,
BDW 2017, Scatto libero. Dino Gavina 10, Palazzo Pepoli Campogrande, Pinacoteca Nazionale di Bologna. (c) Giacomo Maestri.

Bologna Design Week is the prototype of building connections and relationships with the $\mathrm{CCl}$, the world of production and research in the Emilia-Romagna region. Since 2015 , the production of $\mathrm{fi}$ e editions has produced, among the main outcomes shared with the University's Design courses, the recognition of a large group of entrepreneurial realities with which an exchange relationship has been consolidated in terms of consultancy, research, workshops, internships. 


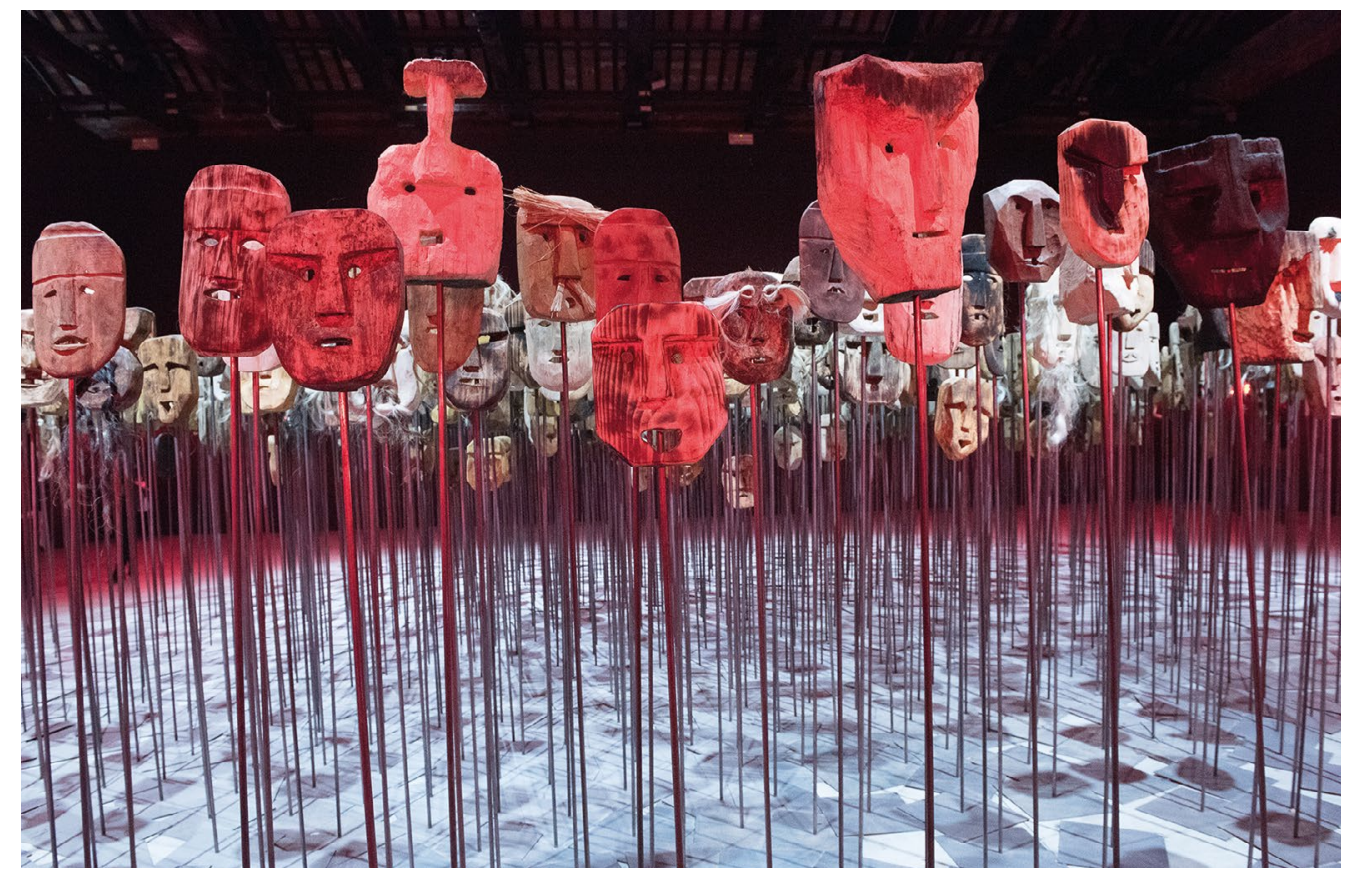

etc.), essential showcases of creativity, capable of creating synergies between institutions and private individuals and becoming models of multi stakeholder ecosystems.

Due to their experimental nature and the mere fact that they take place in spaces throughout the city, design weeks have anticipated visions, proposed new processes of relationship between contents-containers-visitors, generated trends, adopted innovative communication models, informing about a "made in" capable of renewing contents, feeding synergies, building an enabling environment, intrinsically linked to the cultural heritage of the territory.

The creation of value through the matching of skills between designers and companies and the valorisation of the resulting product-services through itinerant exhibitions, have made it possible to design new models of internationalisation of skills, design and production abilities outside the traditional trade fair models (Le French Design by VIA, Denmark Mindcraft Project, Graphic Days, etc.).

The organisation by companies, agencies and design councils of workshops, international competitions and awards (the longest-running of which are the Compasso d'Oro and the Red Dot Award) has amplified the communication of players and productive areas, which are highlighted in catalogues and design museums (Triennale Design Museum; Essen Red Hot Design Museum; ADI Design Index and ADI Design Museum).

Furthermore, the presence of design and cultural and creative sectors in European calls is accelerating the creation of plural consortia which represent pieces of a more articulated system. Finally, the need to investigate this emerging phenomenon with generative and transformative power has multiplied observatories
La Biennale di Venezia, 2018. (c) Gabriele Tubertini.

$$
\rightarrow
$$

Reciprocity design Liège, 2018, Anne Sophie MulIer, ARBA-ESA, Variable Geometries. (C) Christophe Bustin Paroi.

Reciprocity design Liège is an international triennial of design \& social innovation organized by the Culture Department of the Province of Liège, in collaboration with the OPMA Provincial Handicraft $\mathrm{O}$ e and Wallonie Design, the agency for the promotion and internationalization of design, whose committee brings together the main public bodies that support design in Wallonia to build a systemic vision for design and $\mathrm{CCl}$. 


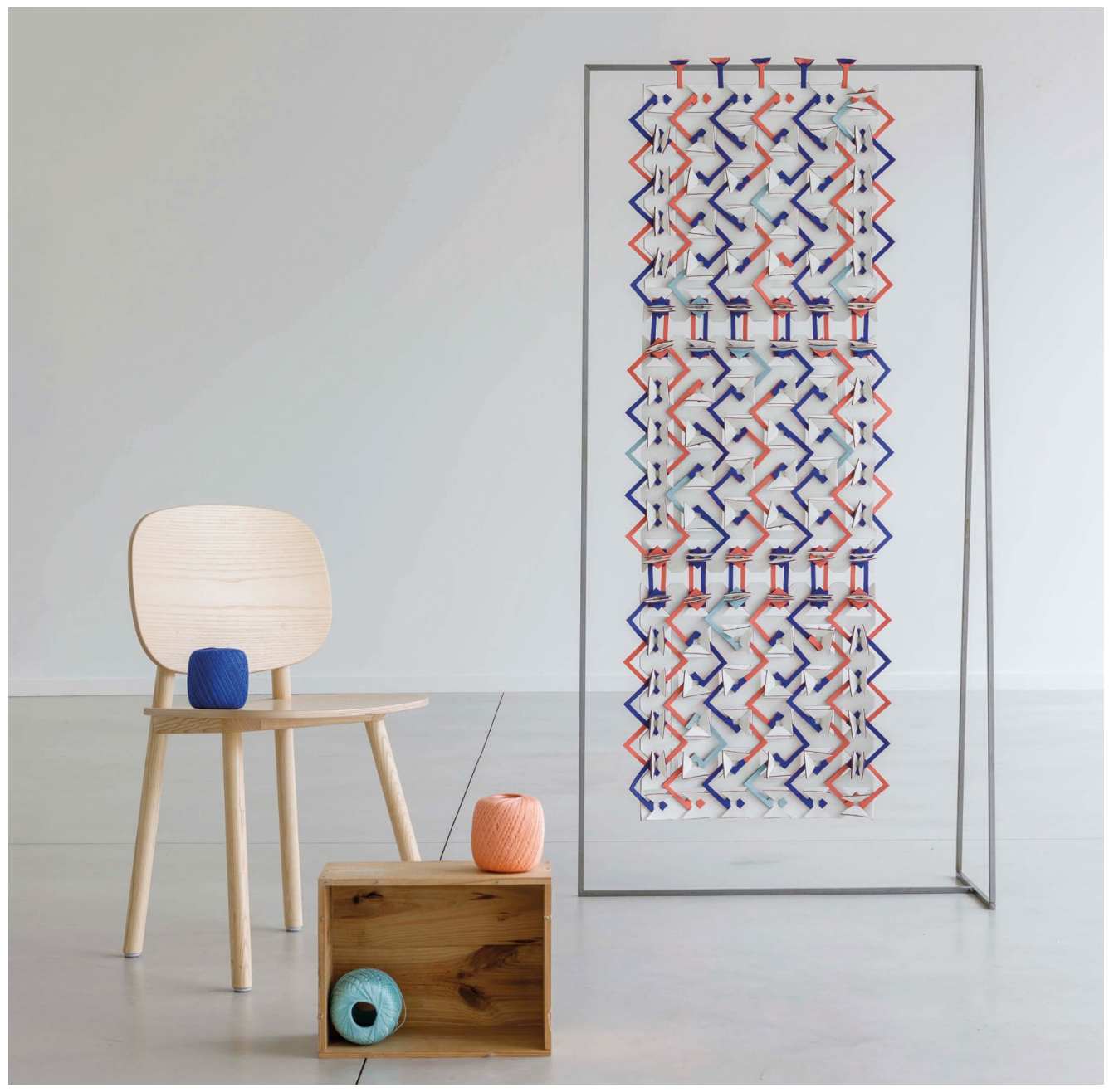

(Cultural and Creative Cities Monitor, 2019) and reports (European Cultural and Creative Cities in COVID-19 times, 2020; Rebuilding Europe. The cultural and creative economy before and after the COVID-19 crisis, 2021).

In this pandemic year, $\mathrm{CCl}$ have been the most responsive in finding innovative solutions to citizens' new needs, but also the most affected by the closure of cultural venues. The different solutions adopted by companies and institutions have been published in platforms to create collective narratives, potential new models for promoting online ecosystems. One example is Creatives Unite (creativesunite.eu/) - a platform launched following a virtual meeting of EU culture ministers (2020) on the pandemic and managed by the European Creative Hubs Network and the Goethe-Institut which brings together initiatives and good practices related to the cultural and creative sectors, offering an opportunity to co-create and share solutions. 
While the crisis has on the one hand cancelled out the sector's operations and activities, it has triggered and accelerated a new form of generation of supranational ecosystems, through online platforms, new reservoirs of relations and co-productions (e.g. Cultural gems ) in which local networks and skills can be exploited globally.

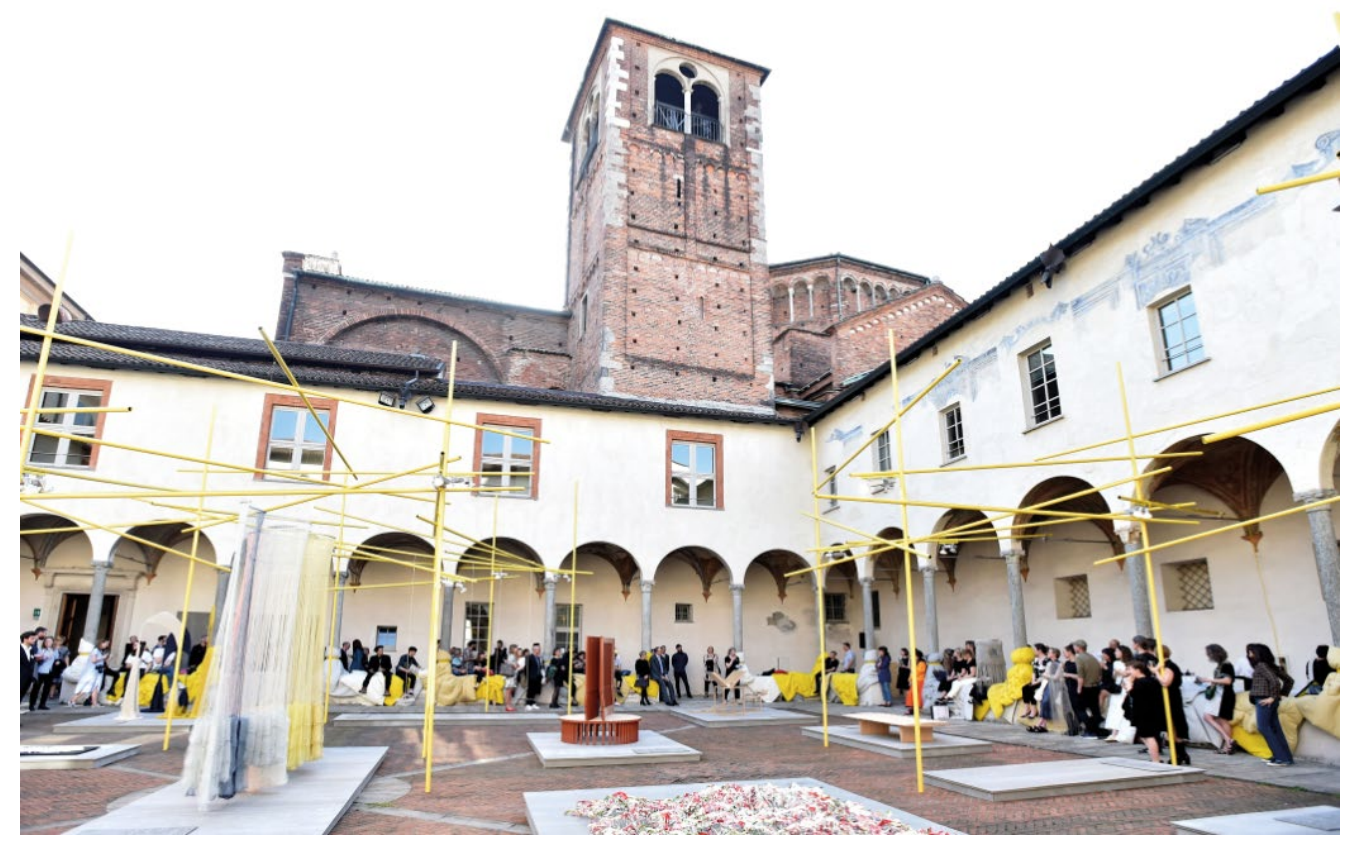

\section{Research Methodology and Characteristics of the Emilia-Romagna Region}

Over the last thirty years, Italy has structured the geopolitics of productive activities through districts and in the last fifteen years has started to formally recognise cultural districts, and thematic clusters more recently.

$\mathrm{CCl}$ are in fact the form through which goods and services are produced essentially everywhere in Italy (Fabris, 2010). However, the identity of the Italian production and cultural system is polarised in certain clichés according to which design is in Milan, industrial automation is in Turin, cultural tourism is in Venice, fashion is in Florence, heritage is in Rome, Mediterranean food is in Naples, etc.

The territory of the Emilia-Romagna Region (RER) has some peculiar characteristics:

- $\quad$ lacks a hierarchical capital city (like Milan for Lombardy²);

- $\quad$ it has in each province an articulated mix of primary, secondary and tertiary activities, research and a rich cultural and demo-ethno-anthropological heritage;

it enjoys widespread prosperity recognised at the highest level in the EU regions;
(C) MINDCRAFT / Jule Hering, San Simpliciano Cloister, Milan Fuorisalone 2018.

Conceived to promote Danish design abroad, MINDCRAFT is a collective exhibition that brings together the skills of craftsmen and companies. The format was conceived by the independent Danish Craft cultural institute which in 2014 merged with the Danish Arts Foundation which organizes the editions and installations entrusted to leading Danish designers and architects together with the Agency for Culture and Palaces. In 2018 the project was sold to the Copenhagen Design Agency. 
- $\quad$ recognized value in every sector of Italian manufacturing (food, fashion, furniture, Ferrari) with excellence and production realities of considerable size;

- $\quad$ RER is the home of cooperation and the whole area has a proud culture of the commons and of the relationship between productive activity and social form;

- $\quad$ it has a production system capable of producing mechatronic and capital goods of recognised high complexity and innovation;

- is logistically strategic in terms of north-south and eastwest relations and it has important road, rail, airport and port infrastructure, with a good spread of digital networks and a high diffusion of education compared to the national average.

Mapping the productive reality of the RER in extreme synthesis, we find ourselves faced with a system of axes which describes a situation of difficult polarisation, between the instrumental dimension (B2B) and the consumer dimension (B2C), as well as between the dimension linked to tradition and the dimension linked to innovation and technological research.

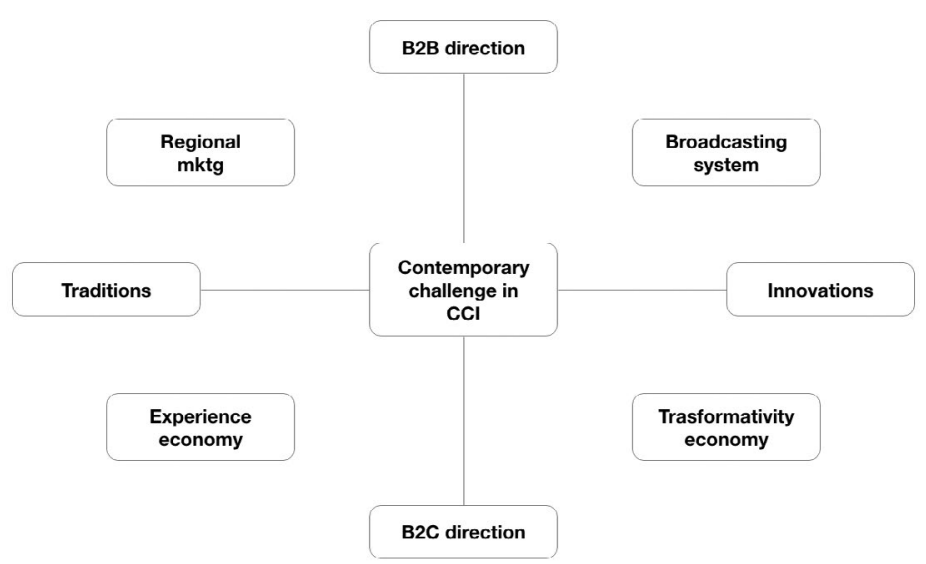

In this area, the system that produces knowledge (universities, research centres), the system that produces goods and services (businesses), and the system of citizens and consumers are still very close and have the capacity to observe each other, recognise each other, speak a familiar language and do things together.

However, the closure of knowledge in armoured silos with little intercommunication does not facilitate $\mathrm{CCl}$ dynamics, based on the interaction between subsystems and knowledge sectors (Germak, 2008).

The functioning model of the $\mathrm{CCl}$ is precisely based on the continuous stitching together of culture, creativity and productive capacity (industry and manufacturing).

But these are, on an international scale, sectors that traditionally have little inclination to interact with each other.
2

Within a radius of 100 $\mathrm{km}$ design is taught at an academic level in Parma, Reggio Emilia, Modena, Ferrara, Faenza, Rimini, San Marino, and Bologna has three active campus (UNIBO, ABABO, IAAD).

Contemporary challenges addressed by $\mathrm{CCl}$. 
During the twentieth century, design developed and demonstrated the ability to use some peculiar capacities to mitigate this incommunicable separation between systems (De Maio, 1997):

- the ability/need to keep one foot in the factory and one in the market;

the need to observe reality acutely, trying to derive simplified and manipulable models;

the continuing need to source knowledge from the four main sources of knowledge (art, technology, economics and management, humanities);

the need to do problem solving but also problem finding where the client does not exist or does not manifest the appropriate issues;

the importance of prefiguring and materialising an idea (vision) around which different languages and knowledge can converge;

the need to experiment and learn by doing, in a continuous and real process that we now call "living lab".

These attitudes are nowadays quite widespread in the world that produces consumer goods, but they are still in a state of experimentation in the world in which designers are called upon to operate on complex systems and processes. These attitudes contribute to generating policies, governance models, development actions, involving citizens and sharing the designer's ability to synthesize identity with an increasingly high and uneven number of people involved.

The project described below was essentially based on practices and articulated in concurrent engineering phases. In seven years, the project has allowed the Region to pass from the previous situation to the birth of a real production sector previously not recognized, up to the positioning of the $\mathrm{CCl}$ as a strategic sector (ERVET, 2018). Finally, the creation of a regional $\mathrm{CCI}$ hub confirms the definitive recognition of the possibility of becoming a $\mathrm{CCl}$ capital at the European level. 
Phase 0 2013-2017 Activation of advanced design courses for the education of a group of young people culturally and pragmatically equipped for complex design; activation of experimental projects based on design of processes and extra-disciplinary knowledge, with the involvement of institutions, businesses and communities of practice; promotion (third mission) of this new profile at local level (industry, society, public administration).
The collaboration with the major urban events in the city of Bologna has been decisive in this phase: trade fairs, Bologna Design Week, events and festivals, seminars and conferences. As well as the development of a capillary organisation of internships for students, placements of young graduates in the most important productive and social realities of the territory.
Phase $1 \quad 2016-2019$
Observation of the context and identification of the main stakeholders and shareholders who can be involved. Political and cultural actionism dedicated to the convergence and analysis of problems and sharing of objectives.

In this phase, the Clust-ER Create was created, bringing together the most significant players in the area who organised themselves into a recognised association with the aim of promoting and supporting system policies.
The development of a systematic relationship with the territorial development agency ASTER (now ARTER) was decisive in opening up international relations in terms of design culture, as opposed to the old vision which linked design only to the sector of products made in Italy and their production chains. This activism and vision led to the birth of the Clust-ER Create, which quickly grew to almost 90 members, integrating large and small enterprises, research centres, institutions and foundations)

Phase 2 2019-2020

Construction of the economic conditions and structured staff to support the project's impact on the territory. This phase went through three different and parallel co-financing actions:

- donations and charitable contributions in support of the project's development purpose;

- participation in competitive research calls, both regional, national and international;

- research and project production commissioned and paid for by companies and foundations.
The most significant element of this phase was the creation of the ADU Advanced Design Unit, i.e. a system of actors capable of integrating different skills and specialisations, which in 2020 reached the number of twenty structured or contracted actors and which in 2019 allowed the launch of a Research Centre dedicated to interaction with the Cultural and Creative Industries (https://site.unibo.it/cricc/it).
Phase 3 2019—ongoing
Once the medium-term stability of the Advanced Design Unit research group was achieved and the network of relations between RER-ARTER-UNIBO-ADU was structured, it has been possible to start the phase of materialisation and systemic reading of the $\mathrm{CCl}$ phenomenon in RER. The process consists in the identification of the excellence of the territory, in the reading of critical phenomena and opportunities that govern the current economic and cultural phase, in the integration of human resources in the most significant projects in progress, continuously supporting the most interesting regional and entrepreneurial innovation policies.
The most tangible results of this period are the development of an articulated system of scientific products intended to create reputation and attention; the implementation of a series of research projects in partnership with local institutions and companies; the development of an organised group of teaching colleagues from various disciplines and in different departments of the Alma Mater Studiorum - Università di Bologna, who came together with the aim of participating in the creation of a KIC (Knowledge Innovation Communities) of European level. 


\section{Conclusions}

Through the narration of the interpretative advanced design model applied to Bologna and the Emilia-Romagna Region, the attempt was to make significant in terms of complexity, temporal dimension, articulation, the research-action that characterises the design of processes for territorial development (Celaschi, 2017).

The process aimed at two objectives: to isolate design within the $\mathrm{CCl}$ phenomena described in European development policies and to use design-oriented practices and cultures to create and develop a recognisable and cohesive $\mathrm{CCl}$ system in the Emilia-Romagna Region (Vai, 2017). This process was based on the need to establish a meaningful relation between the production system (industry), the cultural system and the creative system, which are traditionally and culturally separated in Italy and do not recognise themselves as a single ecosystem, interacting and interoperating.

The process started with the creation of a new academic training area for advanced design within the territory's most important university (the oldest in the western world) and the creation of mediation infrastructures (Advanced Design Unit) and research centres (C.R.I.C.C.) for the interaction and construction of ecosystems for the cultural and creative industries (Formia et al., 2021).

The process was inspired by Alberto Seassaro's vision of the metropolitan city of Milan (1999) and, in the following years, reproduced in other areas (Turin 2008, World Design Capital), and in non-European countries (Porto Alegre, Brazil, 2004-2010; Guadalajara digital 2012-2018).

This model has required a very long interval compared to contemporary expectations of territorial development. Therefore, it will be able to discharge and produce recognisable effects in numbers and economic evidence over the next ten years. The advanced design creation model has asked for a determined direction, which has necessarily had to adapt to the characteristics of the territory, the research context, the historical moment and the negative economic situation, already under way in Italy since 2009 and strongly aggravated by the current pandemic.
Flaviano Celaschi

Flaviano Celaschi, Ph.D.,

Full Professor in Advanced Design, Department of Architecture, Alma Mater Studiorum - Università di Bologna, is president of the Regional Cluster for Creative and Cultural Industries. Since 1995 he works on design processes and cultures in Politecnico di Milano, Politecnico di Torino, Università di Bologna. He is the author of over one hundred scientific products in the field of design driven innovation. Since 2021 he is director of diid.

\section{Elena Vai}

Elena Vai, Ph.D. in Architecture and Design Culture, is coordinator of C.R.I.C.C. (Research Centre for the Interaction with the Cultural and Creative Industries) at the Alma Mater Studiorum - Università di Bologna. Since 1995 she has operated as event designer, curator, mediator and producer of cultural and editorial projects on the topic of Cultural and Creative Industries. Since 2014 she has taught and works in the Advanced Design Unit of the Alma Mater Studiorum - Università di Bologna. 
Austrian Institute for SME Research and VVA Europe (2016). Boosting the competitiveness of cultural and creative industries for growth and jobs. European Union.

Bakhshi, H., Freeman, A., \& Higgs, P. (2013). A Dynamic Mapping of the UK's Creative Industries. Nesta.

Celaschi, F. (2017). II design nel contesto regionale: dal design center al design system. In E. Vai (Ed.), Cultura, creatività, industria. Culture del progetto e innovazione di sistema in Emilia-Romagna (pp. 71-78). Luca Sossella.

CREADIS3 Project (2020). Lessons learnt in CREADIS3. From territorial action plans to Smart Specialization Strategie in cultural and creative districts.

Cultural gems. (2020). https://culturalgems. jrc.ec.europa.eu/culture-from-home-initiatives

De Maio, A. (1997). Qualità del progetto: I criteri di programmazione e Progetto e interdisciplinarietà. In G. Nardi (a cura di), Aspettando il progetto. Franco Angeli.

EIT KIC Culture and Creativity. (2021). https://eit. europa.eu/our-activities/ call-for-eit-communities/2021
E.R.V.E.T. (Ed.). (2018). Economia arancione in Emilia-Romagna report. Cultura Creatività Industria. http://www.ervet. it/ $? p=13363$

European Commission. (2007). European Agenda for Culture. Official Journal of the European Union. https://eur-lex.europa.eu/ LexUriServ/LexUriServ. do?uri=OJ:C:2007:287: 0001:0004:EN:PDF

European Commission. (2009). Official launch of the European Year of Creativity and Innovation 2009. https://ec.europa.eu/ commission/presscorner/ detail/en/IP_09_3

European Commission. (2018). New European Agenda for Culture. https:// ec.europa.eu/culture/document/new-european-agenda-culture-swd2018-267-final

European Commission. (2018). Creative Europe Programme 2021-2027. https:// www.consilium.europa. eu/it/policies/creative-europe-2021-2027/

Fabris, G. (2010). La società post-crescita. Egea.

Florida, R. (2003). The rise of the new creative class. Arnoldo Mondadori Editore.

Formia, E., Celaschi, F., Gianfrate, V., \& Vai, E. (2021). Proximity as space of opportunity: connecting people, productions and territories. Design Cultures. Cumulus Roma 2021. University of Rome.
Gaiani, M. (2017). Design Policy come leva di sviluppo delle Industrie Culturali e Creative: una premessa a base lessicale. In Vai, E. (Ed.). Cultura, creatività, industria. Culture del progetto e innovazione di sistema in Emilia-Romagna (71-78). Luca Sossella.

Germak, C. (Ed.) (2008). L'uomo al centro del progetto. Allemandi.

Howkins, J. (2001/2013) The Creative Economy: How People Make Money from Ideas. Penguin Books.

KEA \& PPMI. (2019). Research for CULT Committee - Culture and creative sectors in the European Unionkey future developments, challenges and opportunities. European Parliament, Policy Department for Structural and Cohesion Policies, Brussels.

Landry, C., \& Bianchini, F. (1995). The creative city. Demos.

Lhermitte, M., Perrin, B., \& Blanc, S. (Eds.). (2015). Cultural times. The first global map of cultural and creative industries. EYGM Limited.

Lhermitte, M., Alvarez, $\mathrm{H}$., Marcout, C., Nam, Q., \& Sauze, E. (Eds.). (2021). Rebuilding Europe. The cultural and creative economy before and after the COVID-19 crisis. EYGM Limited.
Montalto, V., Tacao Moura, C. J., Alberti, V., Panella, F., \& Saisana, M. (2019). The Cultural and Creative Cities Monitor. 2019 edition, EUR 29797 EN, Publications Office of the European Union, Luxembourg, ISBN 978-92-76-088073, doi:10.2760/257371, JRC117336.

Montalto, V., Sacco, P.L., Alberti, V., Panella, F., \& Saisana, M. (2020). European Cultural and Creative Cities in COVID-19 times, EUR 30249 EN, Publications Office of the European Union, Luxembourg, ISBN 978-92-76-194330, doi:10.2760/624051, JRC120876.

Seassaro, A. (1999). Sistema Design Milano, Milano Design System, Abitare Segesta Milano.

Throsby, D. (2001). Economics and Culture. Cambridge University Press.

UNESCO. (2005). Convention on the Protection and Promotion of the Diversity of Cultural Expressions. https://en.unesco.org/ creativity/convention

Vai, E. (Ed.). (2017). Cultura, creatività, industria. Culture del progetto e innovazione di sistema in Emilia-Romagna. Luca Sossella. 